\title{
Science and Religion, Contemporary Scientific Views on Gnosticism, Heresy, Mystic Codes in Great works of Art and Gnostic Symbols such as Discussed in "Code daVinchi" etc
}

ISSN: 2639-0612

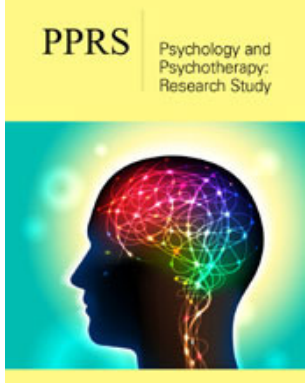

*Corresponding author: Perlovsky L, Department of Psychology, USA

Submission: 眥 February 18, 2020

Published: 眥 February 21, 2020

Volume 3 - Issue 4

How to cite this article: Perlovsky L. Science and Religion, Contemporary Scientific Views on Gnosticism, Heresy, Mystic Codes in Great works of Art and Gnostic Symbols such as Discussed in "Code daVinchi" etc. Psychol Psychother Res Stud. 3(4).PPRS.000567.2020.

DOI: 10.31031/PPRS.2020.03.000567

Copyright@ Perlovsky L, This article is distributed under the terms of the Creative Commons Attribution 4.0 International License, which permits unrestricted use and redistribution provided that the original author and source are credited.

\section{Perlovsky L*}

Department of Psychology, USA

\section{Opinion}

Books like daVinchi Code catch attention of millions of people while at the same time their success puzzle many of us: why ancient ideas, explored for millennia still catch attention of so many people? Here I suggest the reason: this attention relates to the most fundamental unresolved problem of contemporary science and even more, of the entire contemporary culture. This is a question of the fundamental breakdown between science and religion, the failure of the culture to repair this split between two of its most important endeavors. Science appeared at the time of Newton, near 300 years ago, and acquired so much significance that in a recently short time the perceived contradiction between science and religion significantly reduced importance of religion. Some scientists like Dawkins deny religion at all.

I would emphasize that religion existed as long as people existed, and it always been considered a most important aspect of culture. Why science was so important and why it succeeded to reduce the importance of religion so fast? First, I would emphasize that it is not just science in its contemporary understanding, but it is a contemporary thinking emphasizing conscious understanding and logical argument. This way of thinking, or even better, consciousness, appeared more than 3,000 years ago, when it came to supersede the previous prophetic consciousness [1]. In prophetic consciousness, clear conscious thoughts were rare and were taken as obvious truths. But about 3,000 years ago a last prophet, Zeccariah, recognized this as an outdated dangerous way of thinking. He declared that he would expel "prophets from this land, every mother and father ". Gradually conscious, logical thinking has evolved.

Yet most of scientists, including Einstein, think that religion, while turning to unconscious, is important. Carl Jung emphasized that reconciliation between science and religion is required for the very possibility of continuing cultural evolution. Steps in this relation are summarized here. Science emphasizes detailed analysis, leading to logical explanations of phenomena, religion instead strives for a unified understanding of what is the most important, even at the price of not being able to formulate consciously its arguments, Perlovsky LI [2]. A difficult to comprehension idea has been the one of the meaning and purpose of human life. At the same time living without the meaning and purpose is impossible. Religion has been the bridge connecting over this gap between what is required for life and at the same time impossible to understand consciously. The meaning and purpose are a concept at the highest level of the hierarchy of the mind, it is not available directly to consciousness and clarifying this concept is the essence of religion. God is a conceptualized, materialized idea of meaning and purpose. Preliminary experimental confirmation of this conclusion has been obtained in $[3,4]$.

But this truth was unknown and hidden. Even now, after giving a scientific explanation for the relation between religion, science, and working of the mind, and after publishing experimental confirmation of this explanation (even if tentative), I am sure, many of my readers would not accept it. The reason is that topic and concepts that are subjects of this 
discussion are not accessible directly to consciousness. To take this knowledge to heart and accept it as a true part of oneself one need to brood over it for a while, to have a chance to discuss it with friends, to observe that indeed much in life is explained by these ideas, and no other hypothesis will fit. This takes a lot of time. For the same reason quantum laws of nature are difficult to comprehend they are not directly observable.

Since more than 3,000 years ago people' consciousness required conscious and logical explanation of deepest religion truths. It is difficult to comprehend and accept what is not directly available to consciousness $[5,6]$. The knowledge described above must be over and over related to one's experience. Simplifying explanations might be dangerous, because without fully understanding and relating every constituent idea to one's life, it is easy to make an error in one's most important life situations. What I described above is an essence of many years of research on these topics. Topics, which were pondered by people for thousands of years. Today we have an advantage of having the scientific method based on theoretical predictions confirmed by experiments.

\section{References}

1. Perlovsky LI (2017) Music: Passions and cognitive functions. Academic Press. San Diego, CA, USA.

2. Perlovsky LI (2011a) Science and religion: New cognitive findings bridge the fundamental gap.

3. Schoeller F, Perlovsky LI (2016) Aesthetic Chills: Knowledge-acquisition, meaning-making, and aesthetic emotions. Front Psychol 7: 1093.

4. Godel FK (2003) Collected works. In: Solomon F (Ed.), Oxford University Press: New York, USA.

5. Levine DS, Perlovsky LI (2008) Neuroscientific insights on biblical myths: Simplifying heuristics versus careful thinking: scientific analysis of millennial spiritual issues. Zygon, Journal of Science and Religion 43(4): 797-821.

6. Perlovsky LI (2011b) Free will and advances in cognitive science. 